\title{
Evaluation of the Adulteration of Edible and Cosmetic Sunflower Oils by GC-FID and ESI-MS
}

\author{
Luciana P. Manin, ${ }^{\circledR a}$ Jessica S. Pizzo, ${ }^{\circ b}$ Adriela A. Rydlewski, ${ }^{\circledR a}$ Patrícia D. S. Santos, ${ }^{b}$ \\ Marília B. Galuch, ${ }^{\circledR b}$ Caroline D. Zappielo, ${ }^{\circledR b}$ Oscar $O$. Santos ${ }^{\circledR b}$ and \\ Jesuí V. Visentainer ${ }^{\circledR} *, a, b$ \\ aPrograma de Pós-Graduação em Ciência de Alimentos, Universidade Estadual de Maringá(UEM), \\ 87020-900 Maringá-PR, Brazil \\ ${ }^{b}$ Departamento de Química, Universidade Estadual de Maringá (UEM), 87020-900 Maringá-PR, Brazil
}

\begin{abstract}
Sunflower oil has several properties that are valuable to the human skin and health; however, they are target of adulterations. In this study, in order to evaluate the authenticity of edible and cosmetics based on sunflower oils, the triacylglycerol (TAG) profiles using direct infusion electrospray ionization mass spectrometry (ESI-MS), the fatty acid (FA) composition by gas chromatography with flame ionization detection (GC-FID) and principal component analysis, of seven commercial samples were determined and the results obtained were compared with the pure sunflower and soybean oils. Of the seven brands analyzed, just one sample presented only sunflower oil in its composition; two stated in the label soybean addition; and four did not present the real composition of the product in the label. Therefore, GC-FID and ESI-MS analysis in conjunction with principal component analysis (PCA) demonstrated that they are complementary techniques and could be applied in food industries to assess the quality of vegetable oils, since results showed the need for stricter quality control for this product.
\end{abstract}

Keywords: fatty acid composition, lipid profile, quality control, principal component analysis

\section{Introduction}

Sunflower oil is obtained from the seed of the Helianthus annuus L. Sunflower seeds have approximately 24 and $47 \%$ of proteins and lipids, respectively, and its lipid fraction is made up mostly of triacylglycerols (TAGs), monoacylglycerols, diacylglycerols, free fatty acids (FAs), vitamins and pigments. ${ }^{1-4}$

Sunflower oil has a light color, with characteristic odor and flavor. It is used in food preparation, such as salads, stews, preserves and fine dishes, and it has health benefits such as improving cardiovascular health and controlling blood low density lipoprotein (LDL) cholesterol levels. ${ }^{3,5}$ In cosmetics, it is cost-effective to use in face and body moisturizer formulations, with extreme importance for the maintenance of skin health, with moisturizing action and also the modulation of the lipid barrier, used as active ingredients of various cosmetic preparations, such as lotions, creams and body oils emollient. ${ }^{6}$ In addition, studies ${ }^{2,7,8}$ show that sunflower oil has positive effects on burn healing, being

*e-mail: jesuiv@gmail.com safe and easily accessible, besides to help to increase the stratum corneum entirety and the skin hydration, because it is rich in vitamin $\mathrm{E}$ and $\mathrm{n}-3, \mathrm{n}-6$ and n-9 FAs. In the study of Türegün et al., ${ }^{8}$ sunflower oil has shown to be effective, fast, safe and non-irritating in the treatment of burned skin. Besides, if cosmetic sunflower oil is not easily accessible, treatment can also be performed with the edible oil. It has benefits of protecting the skin against infections and against the passage of ultraviolet rays (responsible for the aging of the skin and for causing dangerous diseases, such as skin cancer), it helps to heal wounds, recover surgical cuts and relieve first and second degree burns. ${ }^{9,10}$

Due to the large number of manufactured, exported and imported products, and to the high-value of specific products, there are tampering opportunities on several processing steps ${ }^{11}$ which are considered lucrative crimes. ${ }^{12}$ The fraud by adulteration is the intentional product manipulation aiming at the profit and can cause problems to the consumer health. For vegetable oils, common adulteration include the dilution or replacement of more expensive oils and fats, such as olive oil and sunflower oil with cheaper one as soybean oil..$^{11,13-17}$ Generally, this type 
of adulteration is difficult to determine because of the short database establishing suitable purity criteria for true edible oils and fats. ${ }^{18}$ Besides low-price of refined soybean oil, it has similar physical-chemical characteristics with others marketed refined oils such as sunflower oil. ${ }^{19}$ The Codex Standards determines that refined oils must be clear oil, limpid without sediment, of clear yellow color without specific odor or taste. These characteristics facility the adulteration of soybean oil to sunflower oil since they are marketed with similar physical characteristics. ${ }^{19}$

Considering technology advances, subtle practices of adulteration has increased dramatically. Therefore, food analysis methods must be capable to detect vegetable oil adulteration. ${ }^{18}$ Mass spectrometry (MS) is widely used for the characterization of oil matrices because of its high sensitivity, selectivity and precision. Recently, direct infusion by electrospray ionization mass spectrometry (ESI-MS) method was employed to identify and quantify small (1\%) adulteration in extra virgin olive oil by soybean oil ${ }^{17}$ and intentionally additions of soybean oil ( $>2 \%$ ) to coconut oil. ${ }^{13}$ However, studies ${ }^{14,15,20,21}$ have successfully evaluated adulteration of oily samples only by qualitative analysis of the lipid profile by ESI-MS, since this method is simple, soft, fast, sensitive, minor amounts of sample and solvent are consumed, and sample can be determined with a relative accuracy in qualitative analysis. However, in quantitative analysis, its disadvantages includes matrix effects, which carry to errors in the quantification of the analytes affecting the accuracy, detection, and precision of an analysis procedure..$^{22}$

In conjunction with the ESI-MS technique, gas chromatography with flame ionization detection (GC-FID) is also widely used for analysis of FAs in vegetable oils, due to the fact that its minimum detectable quantity is 10 to $12 \mathrm{~g}$, and its response is a differential, because the magnitude of the signal is proportional to the number of active carbon, and thus, the methyl esters with different carbon chains present different responses in this detection. ${ }^{15,20}$ In addition to
GC-FID, a technique that can assist in verifying adulteration in vegetable oils, is GC-MS, a rapid and non-destructive methodology, which allows the interpretation of multiple variables or chemical compounds simultaneously. ${ }^{23,24}$

Taking into account the relevance of this subject, the aim of this study was to evaluate the quality of seven samples of commercial edible and cosmetic sunflower oils available in the Brazilian market and to identify possible sunflower oil adulterated with large amounts of soybean oil. For that, the fatty acid composition and lipid profiles were determined by GC-FID and ESI-MS, respectively, in order to assess qualitatively the possible adulteration of sunflower oil samples with low-cost soybean oil. Results were compared to those obtained for a pure sample extracted of sunflower and soybean seeds.

\section{Experimental}

\section{Samples}

Five samples of commercial edible and cosmetic sunflower oils, consisting exclusively of sunflower oil (composition on the label), were purchased in the Brazilian market. Two cosmetic samples declared as a mixture of oils (containing sunflower and soybean oils) were purchased in the Brazilian market.

To obtain the pure sunflower oil (SUN), sunflower seeds were purchased from a local market in Maringá (Paraná, Brazil). In addition, refined soybean oil (SO) was purchased in the same region.

Table 1 shows the information provided on the labels about the composition of the commercial samples analyzed.

\section{Obtaining pure sunflower oil (SUN)}

SUN was extracted by cold pressing. ${ }^{25} 100 \mathrm{~g}$ of sunflower seed was dried in a forced-air convection oven

Table 1. Composition provided by the manufacturer of the commercial edible and cosmetic sunflower oils analyzed

\begin{tabular}{lccc}
\hline $\begin{array}{l}\text { Sample of } \\
\text { sunflower oil }\end{array}$ & Product type & Acronym & Composition and additional information ${ }^{\mathrm{a}}$ \\
\hline A & cosmetic & SCA & $100 \%$ pure and natural (Helianthus annus seed oil) \\
B & cosmetic & SCB & $100 \%$ pure and natural (Helianthus annus seed oil) \\
C & cosmetic & SCC & $100 \%$ pure and natural (Helianthus annus seed oil) \\
D & edible & SED & $100 \%$ pure and natural (Helianthus annus seed oil) \\
E & edible & SEE & $100 \%$ pure and natural (Helianthus annus seed oil) \\
F & cosmetic & SCF & sunflower oil (Helianthus annus seed oil), BHT, benzyl salicylate, coumarin \\
& & & cinnamal, hexyl cinnamal, glycine soybean oil, parfum \\
G & cosmetic & SCG & caprylic/capric triacylglycerols, tocopheryl acetate, sunflower oil (Helianthus annuus \\
\end{tabular}

${ }^{a}$ Available on the package label. BHT: dibutylhydroxytoluene. 
(Tecnal, TE-394/3-MP, Piracicaba, SP, Brazil) at $50{ }^{\circ} \mathrm{C}$ for $14 \mathrm{~h}$, and then milled with a mixer (Viva Collection 400W RI136406, Philips Walita, São Paulo, Brazil) to obtain a fine flour, which was placed in a stainless steel cylinder (Metal PEM, PHP 30 tons model, Maringá, Brazil), under a pressure of 10 tons, to extract the sunflower oil, used as reference of pure sunflower oil (SUN). This extraction methodology was based on the work of Pizzo et al. ${ }^{15}$

Fatty acid (FA) composition by gas chromatography with flame ionization detector (GC-FID)

The fatty acid methyl esters (FAMEs) were prepared by methylation of the oils according to Hartman and Lago $^{26}$ and modified by Maia and Rodriguez-Amaya. ${ }^{27}$

For the separation of the FAMEs, a Thermo Scientific Trace Ultra 3300 gas chromatograph (GC, Waltham, United States) with flame ionization detector (FID), a fused silica capillary column CP-7420 (Select FAME, 100 m, $0.25 \mathrm{~mm}$ internal diameter, $0.25 \mu \mathrm{m}$ cyanopropyl thin film as stationary phase) and a split/splitless injector were used. Temperature of the detector was $250^{\circ} \mathrm{C}$ and of the injector was $230{ }^{\circ} \mathrm{C}$. The temperature programming was carried out according to the following steps: $165^{\circ} \mathrm{C}$ for $18 \mathrm{~min}$, followed by a ramp of $4{ }^{\circ} \mathrm{C} \mathrm{min}^{-1}$ to $235{ }^{\circ} \mathrm{C}$ for $20 \mathrm{~min}$. The flow rate of carrier gas $\left(\mathrm{H}_{2}\right)$ was $1.2 \mathrm{~mL} \mathrm{~min}^{-1}$, and $30 \mathrm{~mL} \mathrm{~min}^{-1}$ for the make-up gas $\left(\mathrm{N}_{2}\right)$. For the FID, the flow rates used were 30 and $300 \mathrm{~mL} \mathrm{~min}^{-1}$ of $\mathrm{H}_{2}$ and synthetic air, respectively. $1.0 \mu \mathrm{L}$ of the samples were injected in split mode with a ratio of 1:40. FAs were identified by comparing the retention times with the relative analytical standards (FAME Mix, C4-C24, Sigma-Aldrich, product No. 18919-1AMP, Saint Louis, United States). Results were expressed in relative percentage area determined by Chromquest $^{\mathrm{TM}} 5.0$ software. ${ }^{13}$

\section{Preparation of SUN and SO blends for GC-FID analysis}

Intentional adulterations of SUN by SO were performed with the following percentages of adulterant: $0,1,5,10$, 20, 50, 70, 90 and $100 \%\left(\mathrm{v} \mathrm{v}^{-1}\right)$. The resulting solutions were analyzed by GC-FID.

Triacylglycerol (TAG) profile by direct infusion electrospray ionization mass spectrometry (ESI-MS)

The oil samples were prepared and analyzed based on Silveira et al. ${ }^{17} 950.0 \mu \mathrm{L}$ of chloroform (Synth, São Paulo, Brazil) were added in $50.0 \mu \mathrm{L}$ of the oil sample. Then, in $5.0 \mu \mathrm{L}$ of this solution, $1.0 \mathrm{~mL}$ of a methanol/ chloroform 9:1 $\left(\mathrm{v} \mathrm{v}^{-1}\right)$ solution and $20.0 \mu \mathrm{L}$ of $0.1 \mathrm{~mol} \mathrm{~L}^{-1}$ ammonium formate solution (Sigma-Aldrich, Darmstadt, Germany) were added. Ammonium formate was added in order to obtain TAG ammonium adducts [TAG $\left.+\mathrm{NH}_{4}\right]^{+}$ instead of protonated TAG $[\mathrm{TAG}+\mathrm{H}]^{+}$. Before the direct infusion analysis, each prepared solution was filtered using a hydrophilic polytetrafluoroethylene (PTFE) syringe filter of diameter $13 \mathrm{~mm}$ and pore diameter $0.45 \mu \mathrm{m}$ (Analítica, São Paulo, SP, Brazil).

The prepared oil samples were directly infused into a Xevo TQ-D ${ }^{\mathrm{TM}}$ triple quadrupole mass spectrometer (Waters, Massachusetts, USA) equipped with an electrospray ionization source $\left(\mathrm{Z}\right.$ spray $\left.{ }^{\mathrm{TM}}\right)$, operating in positive mode (ESI+), under the following conditions: infusion flow rate of $50.0 \mu \mathrm{L} \mathrm{min}{ }^{-1}$, desolvation gas flow of $500 \mathrm{~L} \mathrm{~h}^{-1}$, desolvation temperature of $250{ }^{\circ} \mathrm{C}$, source temperature of $150{ }^{\circ} \mathrm{C}$, capillary voltage of $3.00 \mathrm{kV}$ and cone voltage of $35.0 \mathrm{~V}$. The system was programmed to wash itself at each sample analysis with appropriate cleaning solvents, the solvent used was a mixture of chloroform methanol 2:1 $\left(\mathrm{v} \mathrm{v}^{-1}\right)$, infused for $4 \mathrm{~min}$ and $50.0 \mu \mathrm{L} \mathrm{min}{ }^{-1}$, and a white injected in the sequence to check the cleaning efficiency. Besides, the TAG profile of the sunflower oil, soybean oil and commercial samples were evaluated in the mass range from 100 to $1200 \mathrm{~m} / \mathrm{z}$. The TAG results were obtained using MassLynx ${ }^{\mathrm{TM}}$ software.

The TAGs present in samples composition and detected by $\operatorname{ESI}(+)-\mathrm{MS}$ as adducts of ammonium $\left[\mathrm{M}+\mathrm{NH}_{4}\right]^{+}$, were identified using Lipid Maps ${ }^{\circledR}$ database in conjunction with LAMES platform. ${ }^{28}$

\section{Statistical analysis}

FA composition results by GC-FID were submitted to statistical analysis of variance (ANOVA), and the means were compared by Tukey's test with a significance level of 95\% using PAST3 software..$^{29}$ Data and the results obtained by ESI-MS were performed to principal component analysis (PCA) using R studio software. ${ }^{30}$

\section{Results and Discussion}

Fatty acid composition by GC-FID

The FA composition results of the commercial samples that were labeled as pure sunflower oils and as a mixture with other components are shown in Table 2. Besides, Codex Standard for Named Vegetable Oils (CX-STAN 210-1999, amended in 2019) ${ }^{19}$ established a range of the FA composition for some commercially available vegetable oils, such as for sunflower and soybean oils, and their ranges are in Table 2. 
From Table 2, pure sunflower (SUN) and soybean (SO) oils were in accordance with the FA ranges established by Codex Alimentarius. ${ }^{19}$

From Codex Standard for Named Vegetable Oils, ${ }^{19}$ it is possible to observe that the FA composition of soybean and sunflower oils are very similar. However, the $18: 3 n-3$ is one of the most distinctive FA on their composition, since soybean oil is a source of alpha-linolenic acid (LNA). ${ }^{31,32}$ The 18:3n-3 FA should be found up to $0.3 \%$ in sunflower oil, and from 4.5 to $11.0 \%$ for soybean oil, to consider these vegetable oils, into the limits established by Codex Standard for Named Vegetable Oils. ${ }^{19}$ Thus, possible addition of soybean oil can be observed through high amounts of such FA. According to Table 2, for samples labeled as pure sunflower oil (SCA, SCB, SCC, SED and SEE), the SCA, SCB, SCC and SED samples showed the 18:3n-3 FA in a proportion greater than $0.3 \%$ (0.81-6.83\%), being SCC and SED the samples with the highest 18:3n-3 FA amounts ( 6.78 and $6.83 \%$, respectively), only the SEE showed 18:3n-3 FA in the allowed range for pure sunflower oil $(0.27 \%)$.

Besides, other possible evidence of the adulteration of sunflower oil is that 16:0 was found in the range of 9.68-11.17\% in samples SED, SCC and SCB, being these proportions higher than 5-7.6\%, which are allowed for sunflower oil, and between the limits established for soybean oil (8-13.5\%). Samples SEE and SCA presented $16: 0$ in 5.02 and $6.02 \%$, respectively.

According to the manufacturer, the SCA sample is a product consisting exclusively of sunflower oil. From Table 2, it can be seen that the 8:0, 10:0 and 12:0 FAs were found in SCA sample; however, according to the Codex Alimentarius these FAs are not naturally present in sunflower oil, ${ }^{19}$ indicating the lack of information on the product label about that addition.

Triacylglycerols consisting of capric (10:0) and caprylic (8:0) FAs are used in cosmetics due to their dermatological behavior. They can impart skin emollient, besides being good spreading agents. ${ }^{33}$ The label of the SCG sample indicates these TAGs in its composition ("caprylic/capric triacylglycerols", from Table 1). From FA results presented in Table 2, the presence of 8:0 and 10:0 FA in SCG sample was then confirmed.

From Table 1, the label of the sample SCG presented 12:0 FA in its composition, but GC-FID analysis did not detect this FA. The 12:0 FA has antimicrobial properties, helping to protect against contamination by bacteria or fungi. Applying the compound directly to the skin may prevent the growth of these microorganisms..$^{34}$ Therefore, the label of sample SCG is inconsistent with the results obtained.

From Table 2, the samples SCG and SCF presented 4.50 and $4.85 \%$ of $18: 3 n-3$, respectively (allowed in ND-0.3\% for sunflower oil and in 4.5-11\% for soybean oil). Besides, they presented 9.70 and $10.10 \%$ of $16: 0$, respectively (allowed in 5-7.6\% for sunflower oil and in $8-13.5 \%$ for soybean oil). These results are in accordance with the label of the SCG and SCF products, since they are declared as a mixture containing sunflower and soybean oils.

The study of Pizzo et al. ${ }^{15}$ evaluated two samples of cosmetic sunflower oils, and showed that one sample had percentages of FAs close to those found for a pure sunflower oil, as well as according to the ranges established by the Codex Alimentarius. ${ }^{19}$ Already the other sample, the FA composition was distinct, because it presented a high

Table 2. Fatty acid (FA) composition of the commercial samples, SUN and SO, and the FA percentage established by Codex for pure sunflower and soybean oils

\begin{tabular}{|c|c|c|c|c|c|c|c|c|c|c|c|}
\hline \multirow{3}{*}{$\begin{array}{l}\text { Fatty } \\
\text { acid }\end{array}$} & \multicolumn{11}{|c|}{ Fatty acid composition ${ }^{\mathrm{a}} / \%$} \\
\hline & \multicolumn{9}{|c|}{ Commercial samples } & \multicolumn{2}{|c|}{ Codex Alimentarius } \\
\hline & SCA & SED & SEE & SCC & $\mathrm{SCB}$ & SCG & SCF & SUN & SO & $\begin{array}{c}\text { Sunflower } \\
\text { oil }\end{array}$ & $\begin{array}{c}\text { Soybean } \\
\text { oil }\end{array}$ \\
\hline $8: 0$ & $3.34 \pm 0.25^{\wedge}$ & $\mathrm{ND}^{\mathrm{B}}$ & $\mathrm{ND}^{\mathrm{B}}$ & $\mathrm{ND}^{\mathrm{B}}$ & $\mathrm{ND}^{\mathrm{B}}$ & $1.22 \pm 0.10^{\mathrm{A}}$ & $\mathrm{ND}^{\mathrm{B}}$ & $\mathrm{ND}^{\mathrm{B}}$ & $\mathrm{ND}^{\mathrm{B}}$ & ND & ND \\
\hline 10:0 & $3.23 \pm 0.23^{\mathrm{A}}$ & $\mathrm{ND}^{\mathrm{B}}$ & $\mathrm{ND}^{\mathrm{B}}$ & $\mathrm{ND}^{\mathrm{B}}$ & $\mathrm{ND}^{\mathrm{B}}$ & $0.77 \pm 0.04^{\AA}$ & $\mathrm{ND}^{\mathrm{B}}$ & $\mathrm{ND}^{\mathrm{B}}$ & $\mathrm{ND}^{\mathrm{B}}$ & ND & ND \\
\hline 12:0 & $0.73 \pm 0.05^{\mathrm{A}}$ & $\mathrm{ND}^{\mathrm{B}}$ & $\mathrm{ND}^{\mathrm{B}}$ & $\mathrm{ND}^{\mathrm{B}}$ & $\mathrm{ND}^{\mathrm{B}}$ & $\mathrm{ND}^{\mathrm{B}}$ & $\mathrm{ND}^{\mathrm{B}}$ & $\mathrm{ND}^{\mathrm{B}}$ & $\mathrm{ND}^{\mathrm{B}}$ & ND & ND \\
\hline $16: 0$ & $6.02 \pm 0.03^{\AA}$ & $11.17 \pm 0.07^{\mathrm{B}}$ & $5.02 \pm 0.09^{\mathrm{c}}$ & $10.92 \pm 0.38^{\mathrm{B}}$ & $9.68 \pm 0.03^{\mathrm{D}}$ & $9.70 \pm 0.15^{\AA}$ & $10.10 \pm 0.13^{\mathrm{B}}$ & $5.13 \pm 0.01^{\mathrm{c}}$ & $11.63 \pm 0.35^{\text {в }}$ & $5.0-7.6$ & $8.0-13.5$ \\
\hline 18:0 & $3.13 \pm 0.13^{\mathrm{A}}$ & $3.55 \pm 0.24^{\mathrm{ABC}}$ & $3.41 \pm 0.37^{\mathrm{ABC}}$ & $3.49 \pm 0.02^{\mathrm{B}}$ & $3.62 \pm 0.06^{\mathrm{c}}$ & $3.79 \pm 0.12^{\mathrm{AC}}$ & $3.50 \pm 0.14^{\mathrm{A}}$ & $2.96 \pm 0.15^{\mathrm{A}}$ & $3.91 \pm 0.11^{\mathrm{D}}$ & $2.7-6.5$ & $2.0-5.4$ \\
\hline $18: 1 \mathrm{n}-9$ & $22.77 \pm 0.04^{\mathrm{A}}$ & $23.01 \pm 0.22^{A C}$ & $30.07 \pm 0.34^{\mathrm{B}}$ & $23.62 \pm 0.35^{\mathrm{c}}$ & $26.48 \pm 0.24^{\mathrm{D}}$ & $22.95 \pm 0.32^{\mathrm{A}}$ & $28.85 \pm 0.32^{\mathrm{B}}$ & $38.74 \pm 0.03^{\mathrm{E}}$ & $24.10 \pm 0.25^{\mathrm{F}}$ & $14.0-39.4$ & $17.0-30.0$ \\
\hline $18: 2 n-6$ & $59.35 \pm 1.56^{\mathrm{A}}$ & $54.54 \pm 1.25^{\text {B }}$ & $59.60 \pm 1.36^{\mathrm{A}}$ & $54.38 \pm 1.27^{\mathrm{B}}$ & $55.75 \pm 1.10^{\mathrm{B}}$ & $56.15 \pm 2.15^{\mathrm{A}}$ & $51.75 \pm 2.36^{\mathrm{B}}$ & $52.17 \pm 2.17^{\mathrm{B}}$ & $54.29 \pm 1.32^{\mathrm{B}}$ & $48.3-74.0$ & $48.0-59.0$ \\
\hline $18: 3 n-3$ & $0.81 \pm 0.04^{\mathrm{A}}$ & $6.83 \pm 0.28^{\mathrm{B}}$ & $0.27 \pm 0.02^{\mathrm{c}}$ & $6.78 \pm 0.09^{\mathrm{B}}$ & $3.48 \pm 0.20^{\mathrm{D}}$ & $4.50 \pm 0.33^{\mathrm{A}}$ & $4.85 \pm 0.09^{\mathrm{B}}$ & $0.19 \pm 0.02^{\mathrm{E}}$ & $5.95 \pm 0.23^{\mathrm{F}}$ & ND-0.3 & $4.5-11.0$ \\
\hline 20:0 & $0.19 \pm 0.04^{\mathrm{AC}}$ & $0.29 \pm 0.04^{\mathrm{B}}$ & $0.18 \pm 0.01^{\mathrm{A}}$ & $0.25 \pm 0.01^{\mathrm{B}}$ & $0.30 \pm 0.04^{\mathrm{B}}$ & $0.30 \pm 0.09^{\mathrm{AB}}$ & $0.29 \pm 0.03^{\mathrm{A}}$ & $0.18 \pm 0.03^{\mathrm{A}}$ & $0.11 \pm 0.02^{\mathrm{C}}$ & $0.1-0.5$ & $0.1-0.6$ \\
\hline $20: 1 \mathrm{n}-9$ & $\mathrm{ND}^{\mathrm{C}}$ & $0.28 \pm 0.04^{\mathrm{A}}$ & $0.16 \pm 0.02^{\mathrm{B}}$ & $0.22 \pm 0.04^{\mathrm{AB}}$ & $0.25 \pm 0.02^{\AA}$ & $0.23 \pm 0.05^{\mathrm{A}}$ & $0.22 \pm 0.01^{\mathrm{A}}$ & $\mathrm{ND}^{\mathrm{c}}$ & $\mathrm{ND}^{\mathrm{c}}$ & ND-0.3 & ND-0.5 \\
\hline 22:0 & $0.42 \pm 0.02^{\AA}$ & $0.34 \pm 0.03^{\mathrm{B}}$ & $0.66 \pm 0.03^{\mathrm{c}}$ & $0.35 \pm 0.05^{\mathrm{B}}$ & $0.44 \pm 0.01^{\mathrm{A}}$ & $0.40 \pm 0.10^{\mathrm{A}}$ & $0.44 \pm 0.06^{\mathrm{A}}$ & $0.63 \pm 0.07^{\mathrm{c}}$ & $\mathrm{ND}^{\mathrm{D}}$ & $0.3-1.5$ & ND-0.7 \\
\hline
\end{tabular}

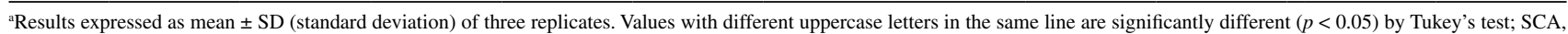
SCB, SCC, SED, SEE, SCF and SCG: commercial samples. SO: soybean oil; SUN: pure sunflower oil; ND: not detected. 
index of 16:0 and 18:3n-3 FAs. It was concluded that the composition of this last sample was similar to soybean oil samples, indicating that this cosmetic was a possible fraud. Comparing the present study with Pizzo et al., ${ }^{15}$ it is possible to observe that the 16:0 FA percentages for samples SED, SCC, SCB, SCG and SCF (9.68 to 11.17\%) were close to the 16:0 FA percentage of the adulterated sample in Pizzo et al. ${ }^{15}$ study (11.77\%). For 18:3n-3 FA, the samples SED, SCC, SCB, SCG and SCF presented high values (3.48-6.83\%) similar to Pizzo et al., ${ }^{15}$ with approximately $5.18 \%$.

\section{Intentional adulterations by GC-FID}

The intentional adulteration of SUN by SO, performed in the following percentage of adulteration: $0,1,5,10$, 20, 50, 70, 90 and $100 \%\left(\mathrm{v} \mathrm{v}^{-1}\right)$ was verified through the results of percentage in relation to the 18:3n-3 FA, present in the Supplementary Information (SI) section (Table S1). Comparing the results obtained from intentional adulteration with the Codex Standard for Named Vegetable Oils, ${ }^{19}$ which shows that sunflower oil can not contain a concentration of the $18: 3 n-3$ FA above $0.3 \%$, with Table S1, it was possible to verify that with $1 \%$ intentional adulteration, it was already possible to detect adulteration, as the value obtained was $0.58 \%$ above what is allowed by Codex. ${ }^{19}$ Also, observing the results in Table 2 of the 18:3n-3 FA of the samples, the only sample that is lower than the concentration range obtained with $1 \%$ was the SEE sample.

\section{Triacylglycerol profile by ESI-MS}

Sunflower and soybean oils have similar FA composition, and it is difficult to evaluate adulteration of the sunflower by soybean oil exclusively from GC-FID analysis. FAs are present in oils in the TAG form: each TAG has three FAs in its molecule, and it is possible to evaluate the entire structure by ESI-MS. TAG profile by ESI-MS of vegetable oils and fats showed to be conclusive in order to detect possible frauds. ${ }^{13-15,17,33,35}$

The lipid profiles of the SUN, SO and commercial samples were acquired by ESI-MS. Figure 1a shows the mass spectrum of the SUN (extracted by pressing), Figure $1 \mathrm{~b}$ shows the mass spectrum of the SO and Figures S1-S7 (SI section) show the mass spectrum of the commercial samples. Table 3 shows TAG ions and relative abundance $(\%)$ for all samples.

Through the TAG profiles presented in Figures 1a-1b and S1-S7, it can be possible to compare the $m / z$ abundances of the sunflower oil samples with the SUN and SO, to verify if there is any possible adulteration.
Figure 1a and Table 3 show that the abundance of the $898 \mathrm{~m} / \mathrm{z}$ TAG is much higher than the $896 \mathrm{~m} / \mathrm{z}$ TAG for SUN. On the other hand, Figure $1 \mathrm{~b}$ and Table 3 show that the abundance of the $896 \mathrm{~m} / \mathrm{z}$ TAG is very close to the abundance of the $898 \mathrm{~m} / \mathrm{z}$ TAG for SO. The possible TAGs of the $898 \mathrm{~m} / \mathrm{z}$ are LLO, SLnL and OLnO; and of the $896 \mathrm{~m} / \mathrm{z}$ are LLL, OLnL, SLnLn and OLnL. Where L is the linoleic acid, $\mathrm{Ln}$ is the linolenic acid, $\mathrm{O}$ is the oleic acid and $S$ is the stearic acid. In Table 3 , it is possible to observe that the $m / z$ TAG of the SO sample with the highest abundance (100\%) was 896 , which the possible TAGs could be LLL, OLnL, SLnLn and OLnL, which is according to the study of Fasciotti and Pereira. ${ }^{36}$

Table 4 shows the ratio between the intensities of the $898 \mathrm{~m} / \mathrm{z}$ and $896 \mathrm{~m} / \mathrm{z}$, in order to assist the observation of possible adulteration of sunflower oil by soybean oil. From Table 4, the $898 / 896 \mathrm{~m} / \mathrm{z}$ ratio for SUN and SO were 1.59 and 0.99 , respectively.

Samples SEE and SCA showed the $898 / 896 \mathrm{~m} / \mathrm{z}$ ratio of 1.65 and 1.50, respectively, which indicates a composition of the 868 and $898 \mathrm{~m} / \mathrm{z}$ close to the SUN. From their TAG profile obtained by ESI-MS (Figures S7 and S1, respectively), and from the abundance of the $872 \mathrm{~m} / \mathrm{z}$ TAG (Table 3), it is observed that SEE and SCA samples are similar to the pure sunflower oil (SUN).

Samples SED and SCC showed the 898/896 $\mathrm{m} / \mathrm{z}$ ratio of 0.97 and 0.92 , respectively, which indicates a composition close to the SO. In addition, the TAG profile of these samples (Figures $\mathrm{S} 2$ and $\mathrm{S} 3$, respectively) are similar to the SO profile; besides, samples SED and SCC presented similar abundance of the TAG LLL $(896 \mathrm{~m} / \mathrm{z}$ TAG) compared to the SO, indicating that these samples contain a great amount of soybean oil in its composition, indicating an adulteration as their packaging declared them as $100 \%$ pure and natural sunflower seed oil.

In this study, samples SCB, SCG and SCF showed the ratio of $1.04,1.07$ and 1.06 , respectively, which indicated an intermediate composition between the SUN and SO. In addition, the TAG profile of these samples presented features of SUN and SO profiles, indicating possible a mixture of sunflower oil and soybean oil in their composition. In fact, SCG and SCF samples were declared (from label) to be as a mixture of SO and SUN. However, the label of the SCB sample did not present this information, featuring an adulteration.

The research of Pizzo et al. ${ }^{15}$ analyzed two samples of commercial sunflower oil in order to monitor possible adulteration with soybean oil. The lipid profile showed a greater $898 / 896 \mathrm{~m} / \mathrm{z}$ ratio for the sample without adulteration and minor ratio for the adulterated sample. 

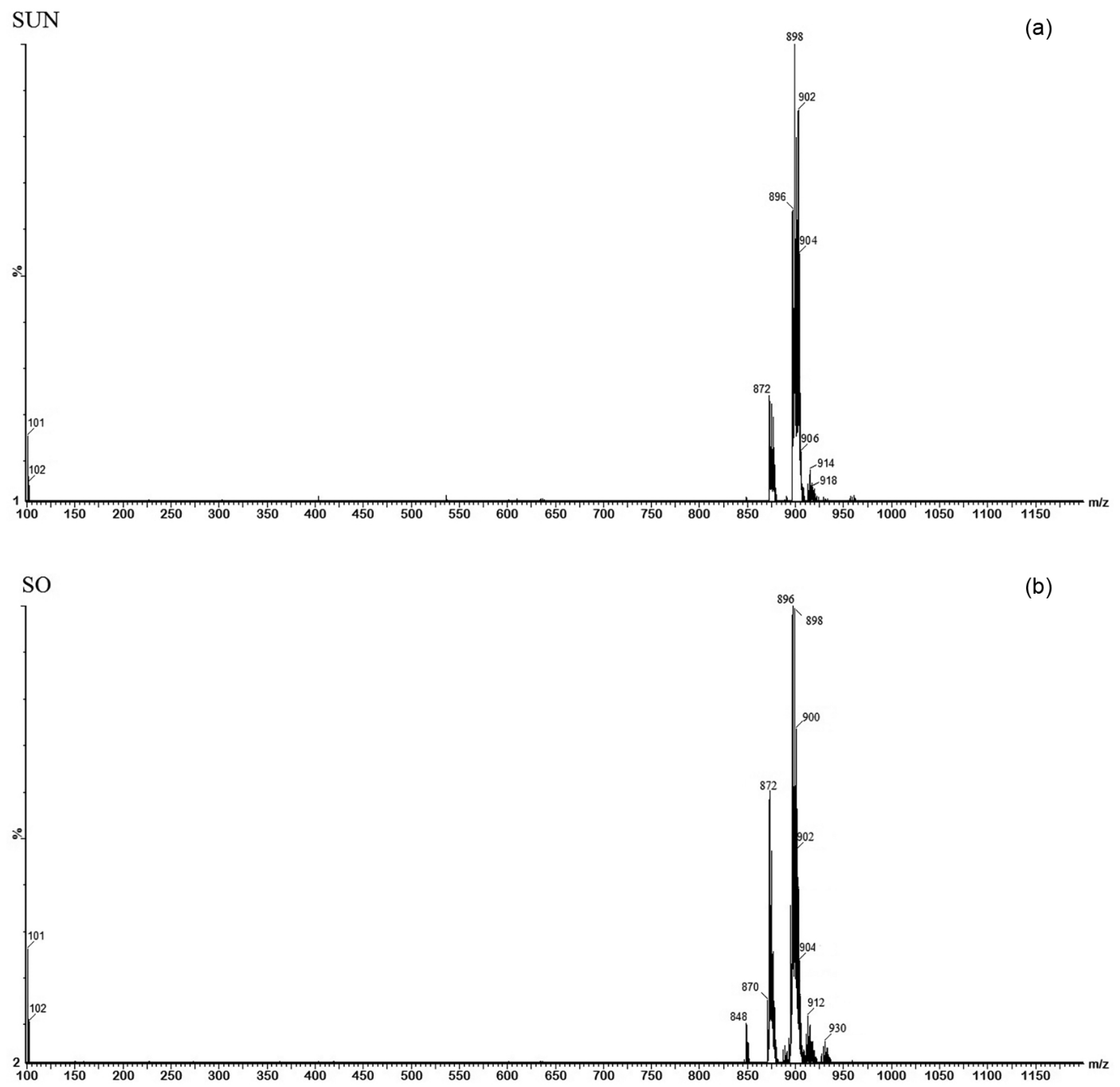

Figure 1. TAG profile by ESI(+)-MS (a) of the pure sunflower oil (SUN); (b) of the soybean oil (SO).

Table 3. Major TAG ions and relative abundance of the commercial samples, pure sunflower oil (SUN) and soybean oil (SO) obtained by ESI(+)-MS

\begin{tabular}{|c|c|c|c|c|c|c|c|c|c|c|}
\hline \multirow{3}{*}[\mathrm{TAG}+\mathrm{NH}_{4}]{$^{+} m / z$} & \multirow{3}{*}{ Possible TAGs ${ }^{\mathrm{a}}$} & \multicolumn{9}{|c|}{ Relative abundance / \% } \\
\hline & & \multicolumn{9}{|c|}{ Sample } \\
\hline & & SCA & SED & SEE & SCC & SCB & SCG & SCF & SUN & SO \\
\hline 488 & $\mathrm{CyCyCy}$ & 50.77 & ND & ND & ND & ND & 34.62 & ND & ND & ND \\
\hline 516 & $\mathrm{CyCyC}$ & 90.01 & ND & ND & ND & ND & 52.39 & ND & ND & ND \\
\hline 544 & $\mathrm{CyCC}$ & 51.89 & ND & ND & ND & ND & 21.42 & ND & ND & ND \\
\hline 572 & $\mathrm{CCC}$ & 7.67 & ND & ND & ND & ND & 2.17 & ND & ND & ND \\
\hline 848 & PLP & 2.94 & 12.57 & 1.91 & 10.38 & 6.88 & 7.60 & 8.83 & 2.18 & 9.75 \\
\hline 870 & LnLP & 2.40 & 15.86 & 1.35 & 15.67 & 8.24 & 10.56 & 11.47 & 0.65 & 15.42 \\
\hline 872 & PLL-PLnO & 30.98 & 38.54 & 31.21 & 39.17 & 27.31 & 28.30 & 31.43 & 27.16 & 35.28 \\
\hline 878 & SOP & 7.60 & 13.49 & 8.89 & 13.75 & 12.04 & 10.56 & 13.64 & 10.81 & 16.30 \\
\hline 896 & LLL-OLnL-SLnLn-OLnL & 66.70 & 100.00 & 60.56 & 100.00 & 96.04 & 93.19 & 94.62 & 62.98 & 100.00 \\
\hline 898 & LLO-SLnL-OLnO & 100.00 & 96.57 & 100.00 & 92.30 & 100.00 & 100.00 & 100.00 & 100.00 & 98.83 \\
\hline 902 & OOO-SLO-SLnS & 39.16 & 37.17 & 44.38 & 35.20 & 36.86 & 35.31 & 38.06 & 49.83 & 42.35 \\
\hline
\end{tabular}

Fatty acid abbreviations: capric acid (C, 10:0); caprylic acid (Cy, 8:0); linoleic acid (L, 18:2n-6); linolenic acid (Ln, 18:3n-6); oleic acid (O, 18:1n-9); palmitic acid (P, 16:0); stearic acid (S, 18:0); SCA, SCB, SCC, SED, SEE, SCF and SCG: commercial samples. SO: soybean oil; SUN: pure sunflower oil; ND: not detected. 
Table 4. Ratio of 898/896 m/z intensities for commercial samples, pure sunflower seed oil (SUN) and soybean oil (SO)

\begin{tabular}{|c|c|c|c|c|c|c|c|c|c|}
\hline \multirow{2}{*}[\mathrm{TAG}+\mathrm{NH}_{4}]{$^{+}$} & \multicolumn{9}{|c|}{ Sample } \\
\hline & SCA & SED & SEE & SCC & SCB & SCG & SCF & SUN & $\mathrm{SO}$ \\
\hline $898 / 896$ & 1.50 & 0.97 & 1.65 & 0.92 & 1.04 & 1.07 & 1.06 & 1.59 & 0.99 \\
\hline
\end{tabular}

SCA, SED, SCC, SCB, SEE, SCG and SCF: commercial samples. SO: soybean oil; SUN: pure sunflower oil.

In relation to the packaging, the SCG label presented that it contains caprylic/capric TAGs in its composition. From its TAG profile (Figure S5, SI section), the addition of the TAGs $488 \mathrm{~m} / \mathrm{z}$ (СyCyCy), $516 \mathrm{~m} / \mathrm{z}$ (СyCyC), $544 \mathrm{~m} / \mathrm{z}$ (CyCC) and $572 \mathrm{~m} / \mathrm{z}$ (CCC) has been confirmed, being $\mathrm{C}$ the capric acid (10:0) and $\mathrm{Cy}$ the caprylic acid (8:0). However, from the TAG profile of the SCA sample (Figure S1, SI section) it was observed the presence of the TAGs CyCyCy, CyCyC, CyCC and CCC in its composition (in accordance with the GC-FID results), but there is no label information about this addition. The SCA sample was presented as a pure and natural sunflower seed oil, showing that the supplier added these TAGs and concealed this information from the consumer.

\section{Principal component analysis (PCA)}

Principal component analysis (PCA) was performed on relative percentage of major TAGs $(848,870,872,878$, 896,898 and $902 \mathrm{~m} / \mathrm{z}$ ) in order to verify the relation with soybean oil and sunflower oil samples once it frequently reveals unexpected associations among variables. Besides, PCA allows interpretation that would not be possible otherwise. Therefore, PCA explained $95.94 \%$ of the total variance. The first component (PC1) accounting for $90.62 \%$ of the total variance, and it was influenced by the TAGs $848,870,878,896$ and $902 \mathrm{~m} / \mathrm{z}$. The second component (PC2, 5.32\%) was defined by the TAGs 872 and $898 \mathrm{~m} / \mathrm{z}$.

Figure 2 demonstrates the association between variables and principal components ( $\mathrm{PC} 1$ versus $\mathrm{PC} 2)$, highlighting the association among the variables. PC1 revealed positive correlation between two clusters (TAG 898 and $902 \mathrm{~m} / \mathrm{z}$ ); and presented negative correlation with five clusters (TAGs 848, 870, 872, 878 and $896 \mathrm{~m} / \mathrm{z}$ ), while PC2 displayed positive correlation with five clusters (TAGs 848, 870, 872, 878 and $902 \mathrm{~m} / \mathrm{z}$ ); and negative correlation with two clusters of variables (TAGs 896 and $898 \mathrm{~m} / \mathrm{z}$ ). Moreover, TAG $878 \mathrm{~m} / \mathrm{z}$ was less correlated with PC2, since its correlation was close to 0. Besides, PCA revealed three distinct groups. Group 1 (SCA, SEE and SUN) was positively correlated to TAG $902 \mathrm{~m} / z$. Group 2 (SCF, SCB and SCG), indicating intermediate values of 896 and $898 \mathrm{~m} / z$. A robust correlation to TAG 848, 870, 872 , and $878 \mathrm{~m} / \mathrm{z}$ was observed in group 3 (SCC, SED and
SO), which showed higher relative percentage of these TAG. Those results showed that the SED and SCC sample showed to be exclusively of soybean oil; SCA and SEE showed to be similar to SUN; and SCF, SCB and SCG are an intermediate with SO and SUN.

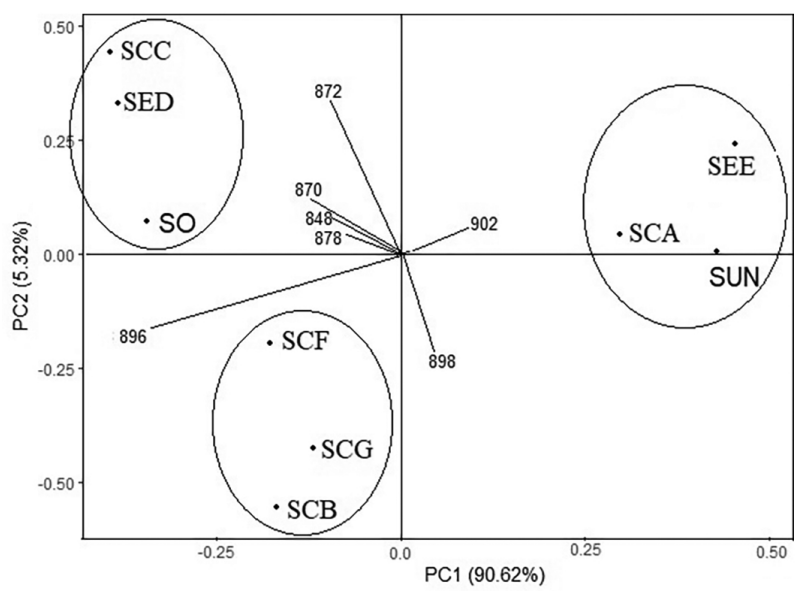

Figure 2. Biplot of PC1-PC2 of the TAGs 848, 870, 878, 896, 872, 898 and $902 \mathrm{~m} / z$ intensities in commercial samples (SCC, SED, SCF, SCG, SCB, SEE and SCA), pure sunflower oil (SUN) and soybean oil (SO).

From Figure 2, it can be possible to observe that lipid profile by ESI-MS (TAG composition) is conclusive compared to GC-FID results (FA composition) in order to verify intentional addition of soybean oil in sunflower oil, since both oils have similar FA composition but distinctive arrangement of FAs for the formation of TAGs.

\section{Conclusions}

The analysis results of GC-FID, ESI-MS, and PCA have shown that the combined techniques are suitable for identifying sunflower oil adulterated with large amounts of soybean oil, because the GC-FID evaluated the FA composition, the ESI-MS verified the TAGs profiles, and the PCA clearly separated groups of soybean oil and sunflower oil samples that showed evidence of adulteration with soybean oil. In addition, the proposed study has also been effective in recognizing major TAGs of soybean oil, sunflower oils and caprylic/capric TAG. In this study, of the seven commercial samples analyzed, one sample (SEE) presented only sunflower oil in its composition; one sample (SCA, declared as pure sunflower oil) presented no soybean 
oil, but presented capric/caprylic TAGs addition; three samples (SCB, SCF and SCG) showed to be a mixture of sunflower oil and soybean oil, but were declared to be as a mixture (SCG and SCF); and two samples (SED and SCC, declared as pure sunflower oil) showed to be only soybean oil. Therefore, results reveal the importance of quality control of cosmetic and edible oils at industries, in order to prevent consumers from acquire adulterated products, believing they are buying pure sunflower oil.

\section{Supplementary Information}

Supplementary data are available free of charge at https://jbcs.sbq.org.br as PDF file.

\section{Acknowledgments}

The authors are grateful to Conselho Nacional de Desenvolvimento Científico e Tecnológico (CNPQ), Coordenação de Aperfeiçoamento de Pessoal de Nível Superior (CAPES), and Fundação Araucária de Apoio ao Desenvolvimento Científico e Tecnológico do Estado do Paraná (FAPPR) for financial assistance.

\section{Author Contributions}

Luciana P. Manin was responsible for conceptualization, investigation, methodology, project administration, writing-original draft; Jessica S. Pizzo for formal analysis, investigation, methodology, resources; Adriela A. Rydlewski for supervision, writing-review and editing; Patrícia S. Santos for data curation, formal analysis; Marília B. Galuch for data curation, formal analysis, writing-review and editing; Caroline D. Zappielo for resources, software, supervision, validation; Oscar Oliveira for conceptualization, project administration, supervision, writing-review and editing; Jesuí Visentainer for project administration, supervision, visualization, writing-review and editing.

\section{References}

1. Redondo-Cuevas, L.; Castellano, G.; Torrens, F.; Raikos, V.; J. Food Compos. Anal. 2018, 66, 221.

2. Sarkar, R.; Podder, I.; Gokhale, N.; Jagadeesan, S.; Garg, V. K.; Int. J. Dermatol. 2017, 56, 1080.

3. Esmael, J.; Worku, A.; Mihiretu, E.; Fentie, D.; Asres, T.; Mekonnen, M.;Alem, C.; Int. J. Plant Breed. Genet. 2016, 10, 104.

4. Angeloni, P.; Echarte, M. M.; Pereyra Irujo, G.; Izquierdo, N.; Aguirrezábal, L.; Field Crop Res. 2017, 202, 146.

5. Jorge, N.; Química e Tecnologia de Óleos Vegetais; Cultura Acadêmica: São Paulo, 2009.
6. Athar, M.; Nasir, S. M.; Afr. J. Biotechnol. 2005, 4, 36.

7. Yamazaki, E.; Shido, K.; Yamasaki, K.; Aiba, S.; Dermatology 2018, 45, 1331.

8. Türegün, M.; Ozturk, S.; Selmanpakoglu, N.; Burns 1997, 23, 442.

9. Manhezi, A. C.; REBEn 2008, 61, 620.

10. Prottey, C.; Haptop, P. J.; Press, M.; J. Invest. Dermatol. 1975, 64, 228.

11. Tibola, C. S.; Silva, S. A.; Dossa, A. A.; Patrício, D. I.; J. Food Sci. 2018, 83, 2028.

12. Moyer, D. C.; DeVries, J. W.; Spink, J.; Food Control 2017, 71, 358

13. Pizzo, J. S.; Galuch, M. B.; Santos, P. D. S.; Manin, L. P.; Zappielo, C. D.; Silva Filho, O. J.; Santos, O. O.; Visentainer, J. V.; J. Braz. Chem. Soc. 2019, 30, 1468.

14. Galuch, M. B.; Carbonera, F.; Magon, T. F. S.; da Silveira, R.; dos Santos, P. D. S.; Pizzo, J. S.; Santos, O. O.; Visentainer, J. V.; J. Braz. Chem. Soc. 2018, 29, 631.

15. Pizzo, J. S.; Galuch, M. B.; Santos, P. D. S.; Santos, O. O.; Visentainer, L.; Eberlin, M. N.; Visentainer, J. V.; J. Braz. Chem. Soc. 2018, 29, 2457.

16. Reske, J.; Siebrecht, J.; Hazebroek, J.; J. Am. Oil Chem. Soc. 1997, 74, 989.

17. Silveira, R.; Vágula, J. M.; Figueiredo, I. L.; Claus, T.; Galuch, M. B.; Santos, O. O.; Visentainer, J. V.; Food Res. Int. 2017, $102,43$.

18. Bell, J. R.; Gillatt, P. N.; Standards to Ensure the Authenticity of Edible Oils and Fats; http://www.fao.org/3/t4660t/t4660t0e. htm, accessed in July 2021.

19. Codex Alimentarius; Standardfor Named Vegetable Oils Codex Stan 210-1999; http://www.fao.org/fao-who-codexalimentarius/ sh-proxy/en/?lnk=1\&url=https $\% 253 \mathrm{~A} \% 252 \mathrm{~F} \% 252 \mathrm{Fwork}$ space.fao.org $\% 252 \mathrm{Fsites} \% 252 \mathrm{Fcodex} \% 252 \mathrm{FStandards} \% 2$ 52FCXS\%2B210-1999\%252FCXS_210e.pdf, accessed in July 2021.

20. Rydlewski, A. A.; Pizzo, J. S.; Manin, L. P.; Galuch, M. B.; Santos, P. D. S.; Zapiello, C.; Santos, O. O.; Visentainer, J. V.; Chem. Pap. 2020, 74, 2799.

21. Pizzo, J. S.; Galuch, M. B.; Manin, L. P.; Santos, P. D. S.; Zappielo, C. D.; Santos Jr., O.; Visentainer, J. V.; Food Addit. Contam., Part A Chem. Anal. Control. Expo. Risk Assess. 2019, 36, 1597.

22. Zhou, W.; Yang, S.; Wang, P. G.; Bioanalysis 2017, 9, 1839.

23. Yang, Y.; Ferro, M. D.; Cavaco, I.; Liang, Y.; J. Agric. Food Chem. 2013, 61, 3693.

24. Fang, G.; Goh, J. Y.; Tay, M.; Lau, H. F.; Li, S. F. Y.; Food Chem. 2013, 138, 1461.

25. Ribeiro, S. A. O.; Nicacio, A. E.; Zanqui, A. B.; Biondo, P. B. F.; de Abreu-Filho, B. A.; Visentainer, J. V.; Gomes, S. T. M.; Matsushita, M.; J. Braz. Chem. Soc. 2016, 27, 834.

26. Hartman, L.; Lago, R. C.; Lab. Pract. 1973, 22, 475. 
27. Maia, E. L.; Rodriguez-Amaya, D. B.; Rev. Inst. Adolfo Lutz. 1993, 53, 27.

28. Filho, N. R. A.; Mendes, O. L.; Lanças, F. M.; Chromatographia 1995, 40, 557.

29. Hammer, Ø.; Harper, D. A. T., Ryan, P. D.; Palaeontol. Electron. 2001, 4,9 .

30. Team, R. C. R.; A Language and Environment for Statistical Computing; Vienna, Austria, 2015.

31. Gebauer, S. K.; Psota, T. L.; Harris, W. S.; Kris-etherton, P. M.; Am. J. Clin. Nutr. 2006, 83, 1526.

32. Kris-Etherton, P. M.; Taylor, D. S.; Yu-Poth, S.; Huth, P.; Moriarty, K.; Fishell, V.; Hargrove, R. L.; Zhao, G.; Etherton, T. D.; Am. J. Clin. Nutr. 2006, 71, 1.
33. Terescenco, D.; Picard, C.; Clemenceau, F.; Grisel, M.; Savary, G.; Colloids Surf., A 2018, 536, 10.

34. Nakatsuji, T.; Kao, M. C.; Fang, J.; Zouboulis, C. C.; Zhang, L.; Gallo, R. L.; Huang, C.; J. Invest. Dermatol. 2009, 129, 2480.

35. Cabral, E. C.; da Cruz, G. F.; Simas, R. C.; Sanvido, G. B.; Gonçalves, L. V.; Leal, R. V. P.; da Silva, R. C. F.; da Silva, J. C. T.; Barata, L. E. S.; da Cunha, V. S.; de França, L. F.; Daroda, R. J.; de Sá, G. F.; Eberlin, M. N.; Anal. Methods 2013, 5, 1385. 36. Fasciotti, M.; Pereira, A. D.; Talanta 2010, 81, 1116.

Submitted: April 9, 2021

Published online: July 14, 2021 